\title{
Effect of Early Tracheostomy on Clinical Outcomes in Patients with Prolonged Acute Mechanical Ventilation: A Single-Center Study
}

\author{
Yewon Kang, M.D. ${ }^{1}{ }^{(i)}$, Wanho Yoo, M.D. ${ }^{1}$, Youngwoong Kim, M.D. ${ }^{2}$, Hyo Yeong Ahn, M.D. ${ }^{3}$, Sang \\ Hee Lee, M.D. ${ }^{4}$ and Kwangha Lee, M.D. ${ }^{1}$ (i) \\ ${ }^{1}$ Division of Pulmonary, Allergy, and Critical Care Medicine, Department of Internal Medicine, Departments of ${ }^{2}$ Trauma \\ Surgery and ${ }^{3}$ Thoracic and Cardiovascular Surgery, Pusan National University School of Medicine, Busan, ${ }^{4}$ Department of \\ Internal Medicine, Wonkwang University Sanbon Hospital, Gunpo, Korea
}

Background: The purpose of this study was to investigate the effect of early tracheostomy on clinical outcomes in patients requiring prolonged acute mechanical ventilation ( $\geq 96$ hours).

Methods: Data from 575 patients (69.4\% male; median age, 68 years), hospitalized in the medical intensive care unit (ICU) of a university-affiliated tertiary care hospital March 2008-February 2017, were retrospectively evaluated. Early and late tracheostomy were designated as 2-10 days and $>10$ days after translaryngeal intubation, respectively.

Results: The 90-day cumulative mortality rate was 47.5\% (n=273) and 258 patients (44.9\%) underwent tracheostomy. In comparison with the late group ( $\mathrm{n}=115)$, the early group $(\mathrm{n}=125)$ had lower 90 -day mortality $(31.2 \% \mathrm{vs.} 47.8 \%$, $\mathrm{p}=0.012)$, shorter stays in hospital and ICU, shorter ventilator length of stay (median, 43 vs. 54; 24 vs. 33; 23 vs. 28 days; all $p<0.001$ ), and a higher rate of transfer to secondary care hospitals with post-intensive care settings ( $67.2 \% \mathrm{vs.} 43.5 \% \mathrm{p}<0.001)$. Also, the total medical costs of the early group were lower during hospital stays than those of the late group (26,609 vs. 36,973 USD, $\mathrm{p}<0.001$ ).

Conclusion: Early tracheostomy was associated with lower 90-day mortality, shorter ventilator length of stay and shorter lengths of stays in hospital and ICU, as well as lower hospital costs than late tracheostomy.

Keywords: Tracheostomy; Mechanical Ventilation; Mortality

Address for correspondence: Kwangha Lee, M.D., Ph.D.

Division of Pulmonary, Allergy, and Critical Care Medicine, Department of Internal Medicine, Pusan National University School of Medicine, 179 Gudeok-ro, Seo-gu, Busan 49241, Korea

Phone: 82-51-240-7743, Fax: 82-51-245-3127

E-mail: jubilate@pusan.ac.kr

Received: Nov. 20, 2019

Revised: Jan. 29, 2020

Accepted: Mar. 2, 2020

(c) It is identical to the Creative Commons Attribution Non-Commercial License (http://creativecommons.org/licenses/by-nc/4.0/).

The Korean Academy of Tuberculosis and Respiratory Diseases.

\section{Introduction}

Advances in the management of acute critically ill patients requiring ventilator care have resulted in an increased number of patients receiving prolonged periods of mechanical ventilation (MV). However, prolonged translaryngeal intubation can result in an increased risk of ventilator-associated pneumonia and sinusitis $^{1,2}$. In addition, severe laryngeal and tracheal damage can be complicated by prolonged translaryngeal intubation ${ }^{3}$. For these reasons, placement of a tracheostomy has become a viable alternative in patients who require prolonged MV.

The development of new and improved instruments, and the standardization of techniques mean that tracheostomy in patients requiring long-term ventilator care is associated with improved patient comfort, reduced sedative drug use, faster 
weaning from $\mathrm{MV}$, reduced incidence of nosocomial pneumonia, and shorter duration of hospitalization ${ }^{4-7}$. Based on these beneficial effects, several studies have investigated the effect of early tracheostomy on patient outcomes ${ }^{8-14}$.

In Korea, critical care delivery systems differ from those in Western countries ${ }^{15,16}$, and the effects of early tracheostomy (ET) on clinical outcomes in patients requiring ventilator care may also differ. A literature review showed no documented definition for ET, and few data have been reported in Korean populations. Therefore, the present study investigated the effect of ET on clinical outcomes in patients requiring prolonged acute mechanical ventilation (PAMV).

\section{Materials and Methods}

\section{Study design and patient selection}

This retrospective study was conducted in the medical intensive care unit (ICU) of a 1,200 bed university-affiliated tertiary care hospital in Busan, Korea. The ICU has full cardiovascular and close airway monitoring equipment, as well as one full-time ICU specialist; the nurse-to-bed ratio is 1:3. All subjects were managed according to therapeutic recommendations, which were based on a lung-protective ventilator strategy $^{17}$. In this hospital, tracheostomy was performed in the ICU by thoracic surgeons in accordance with standard surgical principles by a request of the attending physicians ${ }^{18}$.

Data from patients treated between March 1, 2008 and February 28, 2017 were retrospectively evaluated. The survival status of all patients was obtained until February 28, 2018. All adult subjects ( $\geq 18$ years of age) admitted to all ICUs were screened if they had received ventilator care. PAMV patients were defined as those who had undergone ventilator care for $>96$ hours in the ICU, regardless of tracheostomy ${ }^{19}$. Patients $<18$ years of age and those who received tracheostomy prior to ICU admission were excluded.

All investigators confirmed that the study objectives and procedures were disclosed fully and that they had full access to all data. Case report forms were completed for each included subject and the relevant medical, laboratory, and radiological data were extracted and used to complete a case report form for each patient, after which the data were analyzed.

\section{Data collection}

Demographic and clinical data were obtained retrospectively from the electronic medical records of each subject; these included age, sex, body mass index, length of stay (LOS) in the ICU and hospital, and duration of MV. The severity of illness was measured using the Acute Physiology and Chronic Health Evaluation (APACHE) II score; accompanying organ failure was assessed according to the Sequential Organ Fail- ure Assessment (SOFA) score ${ }^{20,21}$. The APACHE II and SOFA scores were calculated from laboratory and clinical data obtained in the first 24 hours of ICU admission. Charlson's weighted index of comorbidities (WIC) was evaluated to determine concurrent comorbidities prior to admission, as previous studies have demonstrated the prognostic utility of this index in PAMV patients ${ }^{22,23}$.

The tracheostomy status was assessed during the ICU stay, and the period between initiating ventilator care to tracheostomy was evaluated. In the present study, patients receiving tracheostomy 2-10 days after translaryngeal intubation were designated as the early tracheostomy group while patients receiving tracheostomy $>10$ days after intubation were designated as the late tracheostomy group, based on previous reports ${ }^{4,5,11}$.

The main causes of ventilator care were evaluated from the medical records of all enrolled patients; the status of rehabilitation during the hospital stay and the discharge to other hospitals of surviving patients was also captured. In addition, the total medical costs for all medical resources used (including all machines) during the hospital stay (ICU and general ward) were retrieved with the permission of the institutional review board. The cost of each medical intervention was estimated in accordance with the reimbursement scales of the Korean Health Insurance Review and Assessment Service. All costs are shown in US Dollars (USD) at an exchange rate of 1 $\mathrm{USD}=1,136.80$ Korean won (exchange rate on April 4, 2019).

The in-hospital mortality rate and 90-day cumulative mortality rate after tracheostomy were assessed. In-hospital mortality was defined as death prior to hospital discharge, whereas 90-day mortality was defined as mortality within 90 days after the day of ICU admission. For surviving patients discharged from the hospital, the 90-day mortality rate was obtained from the National Health Insurance Service Database.

\section{Outcome measures}

The primary outcome measure was 90-day mortality. Secondary outcome measures were LOS (ICU and hospital), transfer to a post-intensive care setting in a secondary care hospital, and total medical costs during the hospital stay.

\section{Statistical analysis}

Continuous variables are expressed as the median (range) and compared using the Student's t-test or Mann-Whitney U test, as applicable. Categorical variables are expressed as numbers (percentages) and compared using the $\chi^{2}$ test or Fisher's exact test (for small numbers), as applicable. The number of deaths in each of the groups and subgroups was compared using the Fisher's exact test (in-hospital and 90-day mortality), as performed in a previous study ${ }^{9}$. The odd ratios of late tracheostomy to early tracheostomy for 90-day mortality were expressed as $95 \%$ confidence interval. Receiver operation 
characteristic curves and the area under the curve were used, and identification of an optimal cut-off value was based on the maximum Youden's index ${ }^{24}$. Kaplan-Meier estimates of 90day cumulative mortality were stratified according to early tracheostomy status, and curves were compared using log-rank tests. All tests were two-tailed and p-values of $<0.05$ were considered statistically significant. All analyses were performed using SPSS version 24.0 for Windows (IBM Corp., Armonk, NY, USA) and MedCalc version 19.0.7 (MedCalc Software, Ostend, Belgium).

\section{Ethics statement}

The study protocol was approved by the Institutional Review Board of Pusan National University Hospital (1908-007081). Because of the observational nature of the study, the need for informed consent from enrolled subjects or their surrogates was waived. This study had no impact on the treatment of enrolled patients.

\section{Results}

\section{General characteristics of patients with PAMV}

During the study period, 575 patients were eligible for par- ticipation (Figure 1). In the total patient group, the hospital and overall 90-day mortality rates were $38.6 \%(\mathrm{n}=222)$ and $47.5 \%$ ( $\mathrm{n}=273)$, respectively; 258 patients (44.9\%) underwent tracheostomy during the hospital stay, and the median period from the beginning of ventilator care to tracheostomy was 9.5 days (range, $0-37$ days) (Figure 2). Table 1 shows the baseline characteristics of the total patient group, and survivors and nonsurvivor subgroups. Nonsurvivors had higher APACHE

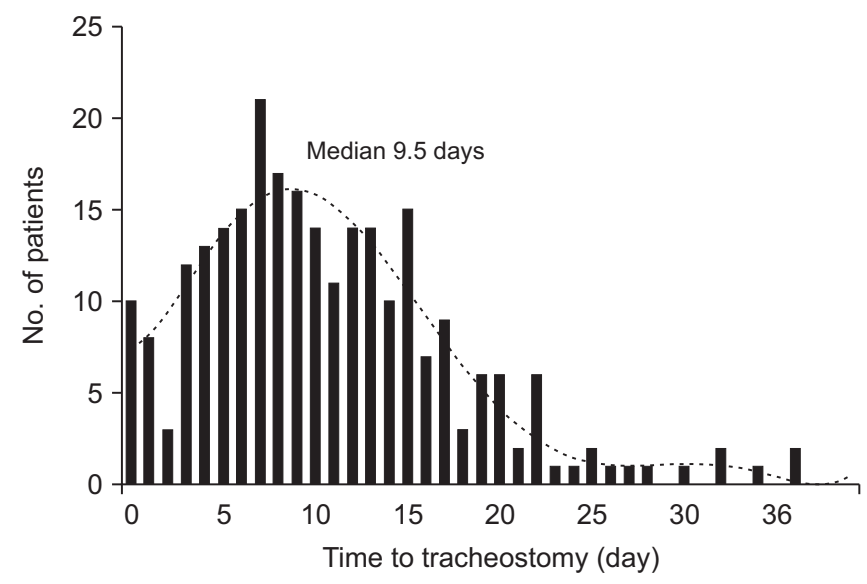

Figure 2. The distribution of tracheostomy timings (from ventilator care to tracheostomy).

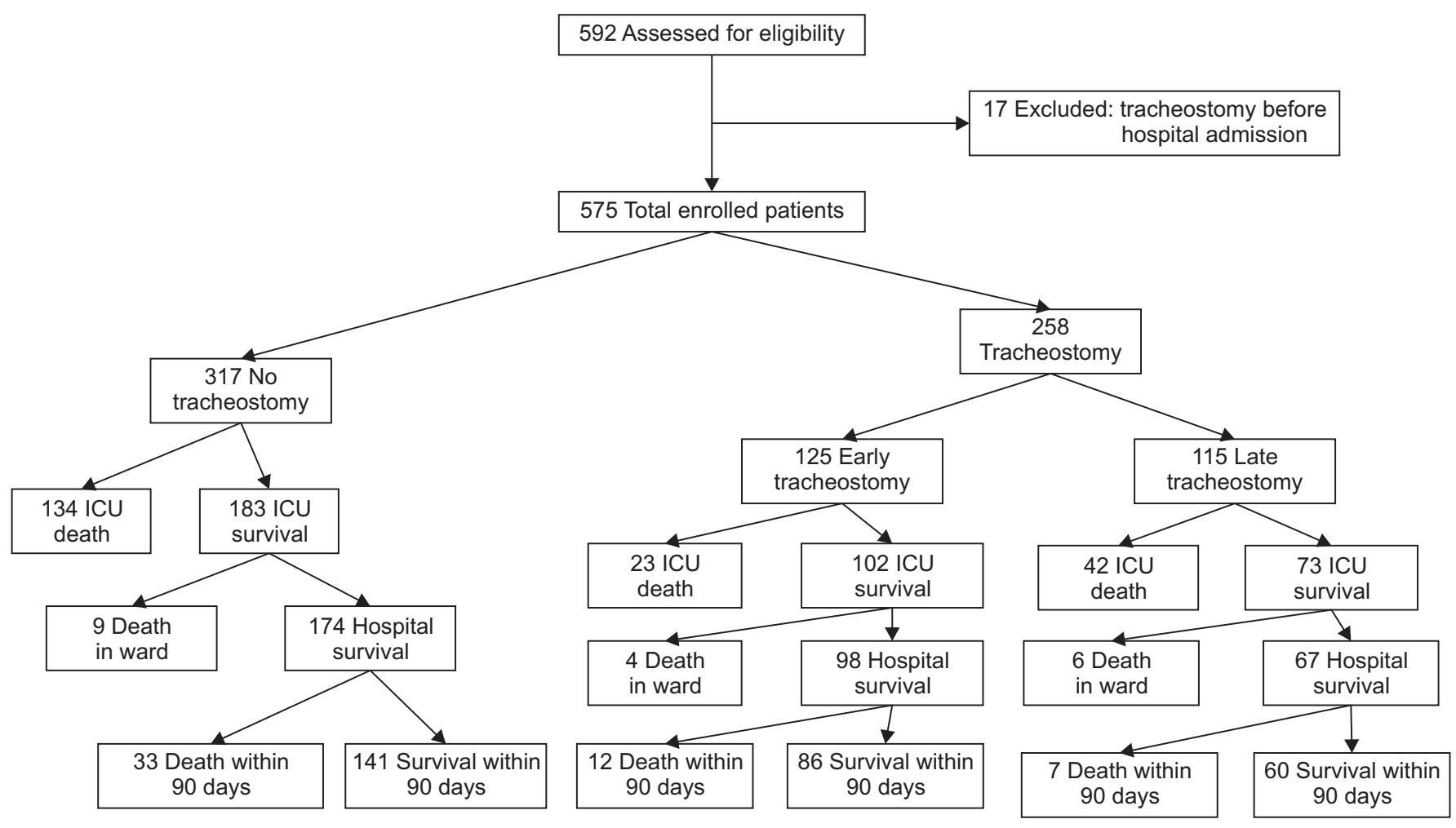

Figure 1. Flow chart of patient selection and clinical course. ICU: intensive care unit. 
Table 1. Baseline patient characteristics and comparisons between survivors and nonsurvivors

\begin{tabular}{|c|c|c|c|c|}
\hline Characteristic & Total $(n=575)$ & Survivors $(n=302)$ & Nonsurvivors $(n=273)$ & p-value \\
\hline Age, yr & $68(18-93)$ & $66(18-93)$ & $71(21-91)$ & $<0.001$ \\
\hline Male sex & $399(69.4)$ & $211(69.9)$ & $188(68.9)$ & 0.856 \\
\hline $\mathrm{BMI} \leq 18.5 \mathrm{~kg} / \mathrm{m}^{2 *}$ & $94(16.3)$ & $38(13.1)$ & $56(21.8)$ & 0.009 \\
\hline APACHE II score ${ }^{\dagger}$ & $20(3-44)$ & $19(3-38)$ & $21(6-44)$ & $<0.001$ \\
\hline SOFA score $^{\dagger}$ & $7(1-19)$ & $6(2-18)$ & $7(1-19)$ & 0.004 \\
\hline Charlson's WIC & $3(0-15)$ & $2(0-14)$ & $4(0-15)$ & $<0.001$ \\
\hline Hospital LOS, day & $30(6-432)$ & $43(6-432)$ & $23(6-90)$ & $<0.001$ \\
\hline ICU LOS, day & $18(4-223)$ & $20(4-223)$ & $17(5-85)$ & 0.002 \\
\hline Duration of MV, day & $13(4-198)$ & $13(4-198)$ & $13(4-83)$ & $<0.001$ \\
\hline \multicolumn{5}{|l|}{ Main causes of ventilator care } \\
\hline Pulmonary diseases & $497(86.4)$ & $263(87.1)$ & $234(85.7)$ & 0.715 \\
\hline Cerebrovascular diseases $^{*}$ & $25(4.3)$ & $14(4.6)$ & $11(4.0)$ & 0.839 \\
\hline Hemato-oncologic emergencies & $15(2.6)$ & $5(1.7)$ & $10(3.7)$ & 0.189 \\
\hline Septic shock & $13(2.3)$ & $5(1.7)$ & $8(2.9)$ & 0.402 \\
\hline Cardiogenic pulmonary edema & $12(2.1)$ & $5(1.7)$ & $7(2.6)$ & 0.563 \\
\hline $\begin{array}{l}\text { Infectious diseases other than respiratory } \\
\text { infections }\end{array}$ & $11(1.9)$ & $5(1.7)$ & $6(2.2)$ & 0.764 \\
\hline Post operation & $10(1.7)$ & $4(1.3)$ & $6(2.2)$ & 0.529 \\
\hline Acute renal failure & $8(1.4)$ & $4(1.3)$ & $4(1.5)$ & $>0.999$ \\
\hline Alimentary diseases & $3(0.5)$ & $1(0.3)$ & $2(0.7)$ & 0.606 \\
\hline Total medical costs during hospital stay (USD) ${ }^{\S}$ & $22,728(2,482-206,636)$ & $24,416(2,482-206,636)$ & $21,588(4,905-99,145)$ & 0.001 \\
\hline
\end{tabular}

Values are presented as medians (range) and number (\%).

*Data from 547 patients (survivors, $n=290$; nonsurvivors, $n=257$ ). ${ }^{\dagger}$ Calculated from clinical data on day of ICU admission. ${ }^{*}$ Included cerebral infarction, subarachnoid hemorrhage, and intracerebral hemorrhage. ${ }^{\S}$ Data from 444 patients (survivors, $\mathrm{n}=240$; nonsurvivors, $\mathrm{n}=204$ ).

BMI: body mass index; APACHE: Acute Physiology and Chronic Health Evaluation; SOFA: Sequential Organ Failure Assessment; WIC: weighted index of comorbidities; LOS: length of stay; ICU: intensive care unit; MV: mechanical ventilation.

II and SOFA scores on ICU admission, and higher Charlson's WIC scores than survivors.

\section{Comparisons between early tracheostomy, late tracheostomy, and no tracheostomy groups}

When the definition of early tracheostomy was applied, 125,115 , and 317 patients were included in the early tracheostomy, late tracheostomy, and no tracheostomy subgroups, respectively. The early tracheostomy group had a higher number of elderly patients and more male patients than the late tracheostomy group. Also, the early tracheostomy group had shorter durations of MV, ICU, and hospital LOS; lower total medical costs during hospital stay; higher Charlson's WIC scores; and a higher rate of transfer to a secondary hospital with post-intensive care settings than the late tracheostomy group (Table 2).

\section{Effect of early tracheostomy on 90-day mortality}

The early tracheostomy group had significantly lower in hospital and 90-day mortality rates than the late tracheostomy group (Table 2). Also, the risk of 90-day mortality was significantly lower for the early tracheostomy group than for the late tracheostomy group (Table 3), and Kaplan-Meier survival analysis showed a significant difference in 90-day morality between the two groups (Figure 3). In addition, in further analyses with some subgroups (male, age $<75$ years, body mass index $[\mathrm{BMI}]>18.5 \mathrm{~kg} / \mathrm{m}^{2}$, and APACHE II score on ICU admission $<25$ ), the early tracheostomy group had a significantly lower 90-day mortality rate (Table 3).

\section{Applications of other definitions of early and late tracheostomy}

Currently, there is no generally accepted definition of early tracheostomy. The present study additionally investigated the 
Table 2. Comparison of clinical characteristics and outcomes according to timing of tracheostomy

\begin{tabular}{|c|c|c|c|c|}
\hline Characteristic & $\begin{array}{l}\text { Early tracheostomy } \\
\qquad(n=125)\end{array}$ & $\begin{array}{l}\text { Late tracheostomy } \\
\qquad(n=115)\end{array}$ & $\begin{array}{l}\text { No tracheostomy } \\
(n=317)\end{array}$ & p-value \\
\hline Male sex & $91(72.8)^{*}$ & $67(58.3)$ & $228(71.9)^{*}$ & 0.016 \\
\hline Age, yr & $72(18-91)^{*}$ & $67(18-91)$ & $68(18-93)$ & 0.033 \\
\hline $\mathrm{BMI} \leq 18.5 \mathrm{~kg} / \mathrm{m}^{2 \dagger}$ & $21(17.8)$ & $16(14.0)$ & $53(17.8)$ & 0.623 \\
\hline APACHE II score $^{*}$ & $22(6-39)$ & $22(8-41)$ & $21(6-44)$ & 0.060 \\
\hline SOFA score ${ }^{*}$ & $7(2-18)$ & $8(1-19)$ & $8(2-19)$ & 0.822 \\
\hline Charlson's WIC & $4(0-14)^{*}$ & $3(0-11)$ & $3(0-15)$ & $<0.001$ \\
\hline Hospital LOS, day & $43(8-260)$ & $54(10-432)^{*}$ & $24(6-380)$ & $<0.001$ \\
\hline ICU LOS, day & $24(7-91)$ & $33(10-201)^{*}$ & $14(4-130)$ & $<0.001$ \\
\hline Duration of MV, day & $23(4-139)$ & $28(4-198)^{*}$ & $9(4-47)$ & $<0.001$ \\
\hline Transfer to secondary care hospitals at discharge & $84(67.2)^{*}$ & $50(43.5)$ & $120(37.9)$ & $<0.001$ \\
\hline Total medical costs during hospital stay (USD) ${ }^{\S}$ & $26,609(2,482-137,879)$ & $36,973(12,721-206,636)^{*}$ & $17,433(2,999-132,890)$ & $<0.001$ \\
\hline Hospital mortality & $27(21.6)$ & $48(41.7)^{*}$ & $143(45.1)^{*}$ & $<0.001$ \\
\hline 90-Day mortality & $39(31.2)$ & $55(47.8)^{*}$ & $175(55.2)^{*}$ & $<0.001$ \\
\hline
\end{tabular}

Values are presented as number (\%) or median (range).

*Values had significantly higher values than the other group(s). 'Data from 529 patients (early [n=118] vs. late [n=114] vs. no [n=297]). ${ }^{*}$ Calcu-

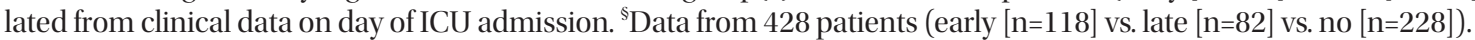

BMI: body mass index; APACHE: Acute Physiology and Chronic Health Evaluation; SOFA: Sequential Organ Failure Assessment; WIC: weighted index of comorbidities; LOS: length of stay; ICU: intensive care unit; MV: mechanical ventilation.

Table 3. Effect of early tracheostomy on 90-day mortality

\begin{tabular}{|c|c|c|c|c|c|c|}
\hline \multirow{2}{*}{ Category } & \multicolumn{2}{|c|}{ Early tracheostomy } & \multicolumn{2}{|c|}{ Late tracheostomy } & \multirow{2}{*}{$\begin{array}{l}\text { Odds ratio of late tracheostomy } \\
\text { to early tracheostomy }(95 \% \mathrm{CI})\end{array}$} & \multirow{2}{*}{$\begin{array}{c}\text { p-value for } \\
\text { Fisher's exact test }\end{array}$} \\
\hline & No. $(\%)$ & $95 \% \mathrm{CI}$ & No. $(\%)$ & $95 \% \mathrm{CI}$ & & \\
\hline All patients $(\mathrm{n}=240)$ & $39(31.2)$ & $22.2-42.7$ & $55(47.8)$ & $36.0-62.3$ & $2.021(1.194-3.422)$ & 0.012 \\
\hline \multicolumn{7}{|l|}{ Subgroups* } \\
\hline Male sex & $28(30.8)$ & $20.5-44.8$ & $33(49.3)$ & $33.9-69.2$ & $2.184(1.136-4.199)$ & 0.021 \\
\hline Age $<75 \mathrm{yr}^{\dagger}$ & $16(19.8)$ & $11.3-32.1$ & $40(43.5)$ & $31.1-59.2$ & $3.125(1.575-6.199)$ & 0.001 \\
\hline $\mathrm{BMI}>18.5 \mathrm{~kg} / \mathrm{m}^{2}$ & $30(30.9)$ & $20.9-44.2$ & $46(46.9)$ & $34.4-62.6$ & $1.976(1.100-3.548)$ & 0.028 \\
\hline APACHE II score $<25^{\dagger}$ & $23(26.4)$ & $16.8-39.7$ & $35(44.9)$ & $31.3-62.4$ & $2.265(1.179-4.351)$ & 0.015 \\
\hline
\end{tabular}

*In all subgroups analyses, data were from 158 (early [n=91] vs. late [n=67]), 173 (81 vs. 92), 195 (97 vs. 98 ), 165 (87 vs. 78 ), and 150 (69 vs. 81 ) patients (from top to bottom). 'The cut-off level was 75 based on Youden's index (AUC, 0.629; 95\% CI, 0.564-0.690; p=0.001; sensitivity, 80.1; specificity, 40.4\%). ${ }^{*}$ Calculated from clinical data on day of ICU admission. The cut-off level was 25 based on Youden's index (AUC, 0.568; 95\% CI, 0.503-0.632; $\mathrm{p}=0.070$; sensitivity, 73.3; specificity, 38.3\%).

CI: confidence interval; BMI: body mass index; APACHE: Acute Physiology and Chronic Health Evaluation; AUC: area under the curve.

effect of early tracheostomy on clinical outcomes using two other definitions of early tracheostomy reported previously ${ }^{9,14}$ : In the Young et al's study ${ }^{9}$, early tracheostomy was performed within 4 days ( $\leq 4$ days) of translaryngeal intubation, and late tracheostomy was performed after 10 days $(\geq 10)]$, whereas in the Shaw and Santry's study ${ }^{14}$, early tracheostomy was performed within 6 days ( $\leq 6$ days) of translaryngeal intubation and late tracheostomy was performed after 11 days $(\geq 11$ days). When these definitions were applied to our patients, the early tracheostomy groups had shorter durations of MV, ICU, and hospital LOS, as well as lower total medical costs during hospital stay than the late tracheostomy groups. Also, the late tracheostomy groups had higher Charlson's WIC scores and a higher rate of transfer to secondary hospitals with post-intensive care settings. Although all early tracheostomy groups showed lower in-hospital mortality, there were no significant differences in 90-day mortality (Supplementary Table S1). 


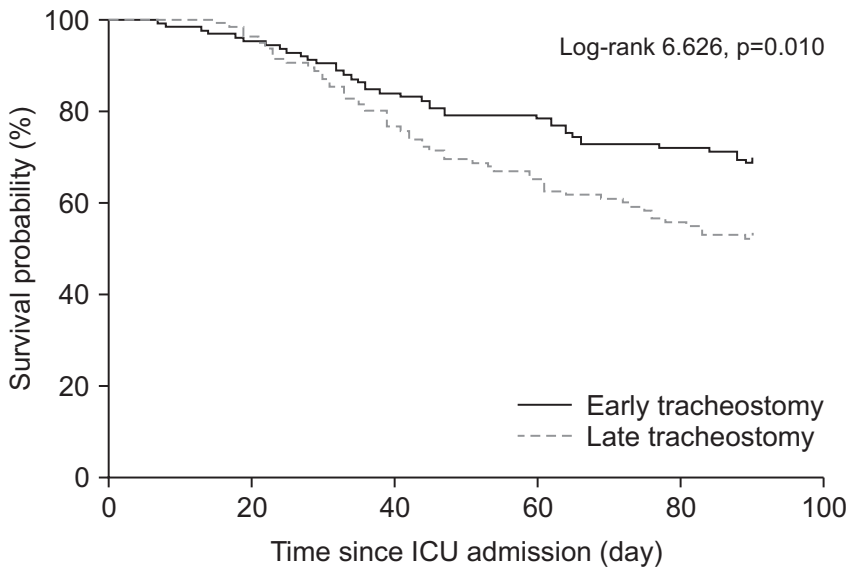

Figure 3. Kaplan-Meier survival curves of 90-day survival after intensive care unit (ICU) admission. Early tracheostomy was performed 2-10 (2-10) days whereas late tracheostomy was performed $10(>10)$ days after translaryngeal intubation.

\section{Discussion}

The present study evaluated the effect of early tracheostomy on clinical outcomes in Korean PAMV patients admitted to a medical ICU, which revealed that early tracheostomy was associated with lower 90-day mortality than late tracheostomy. Also, the early tracheostomy group had lower 90-day mortality; shorter durations of MV, ICU, and hospital LOS; and lower total medical costs during hospital stay than the late tracheostomy group. In addition, when patients were analyzed using two other definitions of early tracheostomy, similar results were obtained. Although there were differences in the demographic data, the early tracheostomy group had better outcomes, which is consistent with previous reports ${ }^{8-14,25}$.

Currently, there is no generally accepted definition of early tracheostomy, and the optimal time for tracheostomy has not yet been established ${ }^{5}$. When we used other definitions of early tracheostomy ${ }^{9,14}, 90$-day mortality rates had no significant difference between the early and late tracheostomy groups. Therefore, large-scale, multicenter studies will be required to establish the optimal timing of tracheostomy and the effect of early tracheostomy on outcomes.

In the present study, we found that the early tracheostomy group had lower 90-day mortality when some subgroups were analyzed (male patients, younger age $[<75$ years], not underweight $\left[\mathrm{BMI}>18.5 \mathrm{~kg} / \mathrm{m}^{2}\right]$ and APACHE II score on ICU admission <25). Our study indicates that ventilated patients with non-frailty or lower severity-of-illness at ICU admission would benefit from early tracheostomy. Further studies will be necessary to evaluate the clinical variables that predict benefit from early tracheostomy.

Our results showed that patients in the early tacheostomy group were more likely to be transferred to secondary care hospitals. Compared with Western countries, however, longterm hospital-based care settings for continuous weaning and management are insufficient in South Korea ${ }^{15,16}$. Our findings also suggest that better care planning after transfer to a secondary hospital is required to validate the effect of early tracheostomy on patients' long-term prognosis.

A review of the literature shows that tracheostomy is performed in 10\%-15\% of patients undergoing MV, and the incidence has been increasing ${ }^{4,5,26,27}$. One study has reported that up to $34 \%$ of patients requiring MV for more than 48 hours receive a tracheostomy ${ }^{28}$. In the current study, tracheostomy was performed in $44.9 \%$ of patients receiving $\mathrm{MV}$, which appears to be higher than that reported in the previous studies $^{4,5,24-26}$. Moreover, tracheostomy was significantly higher in patients who survived more than 90 days $(62.0 \%$ vs. $44.8 \%$ in nonsurvivors, $p<0.001$ ). These findings raise several considerations. First, the tertiary care hospital where the research was conducted has a relatively small number of ICU beds (being a 12 bed medical ICU) in comparison with the size of the hospital, and the shortage of ICU beds is a daily problem when caring for acutely ill patients. Second, the proportion of older patients ( $\geq 65$ years) was $62.3 \%(n=358)$, which could be associated with delayed recovery from acute critical illness and an increased incidence of accompanying delirium. Third, the nursing staff and full-time intensivists in the ICUs of Korean university and teaching hospitals are less robust than their counterparts in Western countries ${ }^{15,16}$. Also, there is no established well-defined MV weaning protocol. In these circumstances, tracheostomy has a number of advantages, including improved lung mechanics, easier oral hygiene, diminished nociceptive stimuli on the larynx or trachea, decreased need for sedatives, enhanced communication, and the fact that the head and neck area is free of equipment ${ }^{4,6-8}$. In addition, tracheostomized patients with lower inspiratory pressure and oxygen requirement could be managed with a home ventilator on a general ward. As a consequence, attending physicians' decision to perform a tracheostomy would be based on a higher probability of patient survival during their ICU course. Therefore, the present study suggests that nationalized guidelines for tracheostomy must be established to allow for better decision-making between attending physicians and patients or their surrogates.

Our study has several limitations. First, the retrospective design of the study may have resulted in selection bias. Second, we could not accurately evaluate whether early tracheostomy would be beneficial in terms of duration of sedation, amount of sedative agent required, and incidence of ventilator-associated pneumonia. Finally, the data were obtained from a single center, and the sample size was small, so the results may not be representative of the wider PAMV population in Korea.

In conclusion, analysis of the effect of early tracheostomy on patient outcomes showed that early tracheostomy was associated with lower 90-day mortality. Also, the early tracheostomy 
group had shorter durations of MV, ICU, and hospital LOS, as well as lower total medical costs during hospital stay than the late tracheostomy group. To identify the effect of early tracheostomy on patient outcomes in Korea, nationalized guidelines for tracheostomy as well as large-scale multicenter studies are warranted.

\section{Authors' Contributions}

Conceptualization: Lee K. Methodology: Kang Y, Yoo W, Kim Y, Ahn HY, Lee SH, Lee K. Formal analysis: Lee K, Kang Y. Data curation: Kang Y, Yoo W, Kim Y, Ahn HY, Lee SH. Software: Lee K, Kang Y. Validation: Lee K, Kang Y, Ahn HY. Investigation: Lee K, Kang Y, Yoo W, Kim Y, Lee SH. Writing original draft preparation: Lee K, Kang Y. Writing - review and editing: Lee K. Approval of final manuscript: all authors.

\section{Conflicts of Interest}

No potential conflict of interest relevant to this article was reported.

\section{Acknowledgments}

We thank Eun Suk Jeong (clinical research nurse) for assistance in the chart review.

\section{Funding}

This work was supported by a clinical research grant from Pusan National University Hospital in 2019.

\section{Supplementary Material}

Supplementary material can be found in the journal homepage (http://www.e-trd.org).

Supplementary Table S1. Comparison of clinical characteristics and outcomes between the early and late tracheostomy groups according to other definitions.

\section{References}

1. Ranes JL, Gordon SM, Chen P, Fatica C, Hammel J, Gonzales JP, et al. Predictors of long-term mortality in patients with ventilator-associated pneumonia. Am J Med 2006;119:897.

2. Holzapfel L, Chevret S, Madinier G, Ohen F, Demingeon G, Coupry A, et al. Influence of long-term oro- or nasotracheal intubation on nosocomial maxillary sinusitis and pneumonia: results of a prospective, randomized, clinical trial. Crit Care Med 1993;21:1132-8.

3. Cavaliere S, Bezzi M, Toninelli C, Foccoli P. Management of post-intubation tracheal stenoses using the endoscopic approach. Monaldi Arch Chest Dis 2007;67:73-80.

4. Cheung NH, Napolitano LM. Tracheostomy: epidemiology, indications, timing, technique, and outcomes. Respir Care 2014;59:895-915.

5. Aquino Esperanza J, Pelosi P, Blanch L. What's new in intensive care: tracheostomy-what is known and what remains to be determined. Intensive Care Med 2019;45:1619-21.

6. Diehl JL, El Atrous S, Touchard D, Lemaire F, Brochard L. Changes in the work of breathing induced by tracheotomy in ventilator-dependent patients. Am J Respir Crit Care Med 1999;159:383-8.

7. Freeman BD, Morris PE. Tracheostomy practice in adults with acute respiratory failure. Crit Care Med 2012;40:2890-6.

8. Hosokawa K, Nishimura M, Egi M, Vincent JL. Timing of tracheotomy in ICU patients: a systematic review of randomized controlled trials. Crit Care 2015;19:424.

9. Young D, Harrison DA, Cuthbertson BH, Rowan K; TracMan Collaborators. Effect of early vs late tracheostomy placement on survival in patients receiving mechanical ventilation: the TracMan randomized trial. JAMA 2013;309:2121-9.

10. Siempos, II, Ntaidou TK, Filippidis FT, Choi AM. Effect of early versus late or no tracheostomy on mortality and pneumonia of critically ill patients receiving mechanical ventilation: a systematic review and meta-analysis. Lancet Respir Med 2015;3:150-8.

11. Andriolo BN, Andriolo RB, Saconato H, Atallah AN, Valente O. Early versus late tracheostomy for critically ill patients. Cochrane Database Syst Rev 2015;1:CD007271.

12. Szakmany T, Russell P, Wilkes AR, Hall JE. Effect of early tracheostomy on resource utilization and clinical outcomes in critically ill patients: meta-analysis of randomized controlled trials. Br J Anaesth 2015;114:396-405.

13. Herritt B, Chaudhuri D, Thavorn K, Kubelik D, Kyeremanteng $\mathrm{K}$. Early vs. late tracheostomy in intensive care settings: impact on ICU and hospital costs. J Crit Care 2018;44:285-8.

14. Shaw JJ, Santry HP. Who gets early tracheostomy? Evidence of unequal treatment at 185 academic medical centers. Chest 2015;148:1242-50.

15. Kwak SH, Jeong CW, Lee SH, Lee HJ, Koh Y. Current status of intensive care units registered as critical care subspecialty training hospitals in Korea. J Korean Med Sci 2014;29:431-7.

16. Lim CM, Kwak SH, Suh GY, Koh Y. Critical care In Korea: present and future. J Korean Med Sci 2015;30:1540-4.

17. Acute Respiratory Distress Syndrome Network, Brower RG, Matthay MA, Morris A, Schoenfeld D, Thompson BT, et al. Ventilation with lower tidal volumes as compared with traditional tidal volumes for acute lung injury and the acute respiratory distress syndrome. N Engl J Med 2000;342:1301-8. 
18. Zollinger RJ, Ellison E. Zollinger's atlas of surgical operations. 10th ed. New York: McGraw-Hill Education; 2016.

19. Zilberberg MD, Luippold RS, Sulsky S, Shorr AF. Prolonged acute mechanical ventilation, hospital resource utilization, and mortality in the United States. Crit Care Med 2008;36: 724-30.

20. Knaus WA, Draper EA, Wagner DP, Zimmerman JE. APACHE II: a severity of disease classification system. Crit Care Med 1985;13:818-29.

21. Vincent JL, Moreno R, Takala J, Willatts S, De Mendonca A, Bruining H, et al. The SOFA (Sepsis-related Organ Failure Assessment) score to describe organ dysfunction/failure. On behalf of the Working Group on Sepsis-Related Problems of the European Society of Intensive Care Medicine. Intensive Care Med 1996;22:707-10.

22. Charlson ME, Pompei P, Ales KL, MacKenzie CR. A new method of classifying prognostic comorbidity in longitudinal studies: development and validation. J Chronic Dis 1987;40:373-83.

23. Song SE, Lee SH, Jo EJ, Eom JS, Mok JH, Kim MH, et al. The prognostic value of the Charlson's comorbidity index in pa- tients with prolonged acute mechanical ventilation: a single center experience. Tuberc Respir Dis 2016;79:289-94.

24. Perkins NJ, Schisterman EF. The inconsistency of "optimal" cutpoints obtained using two criteria based on the receiver operating characteristic curve. Am J Epidemiol 2006;163:6705.

25. Raimondi N, Vial MR, Calleja J, Quintero A, Cortes A, Celis E, et al. Evidence-based guidelines for the use of tracheostomy in critically ill patients. J Crit Care 2017;38:304-18.

26. Frutos-Vivar F, Esteban A, Apezteguia C, Anzueto A, Nightingale P, Gonzalez M, et al. Outcome of mechanically ventilated patients who require a tracheostomy. Crit Care Med 2005; 33:290-8.

27. Mehta AB, Syeda SN, Bajpayee L, Cooke CR, Walkey AJ, Wiener RS. Trends in tracheostomy for mechanically ventilated patients in the United States, 1993-2012. Am J Respir Crit Care Med 2015;192:446-54.

28. Quality of Life After Mechanized Ventilation in the Elderly Study I. 2-month mortality and functional status of critically ill adult patients receiving prolonged mechanical ventilation. Chest 2002;121:549-58. 